\title{
The Impact of Heavy (Excessive) Video Gaming Students on Peers and Teachers in the School Environment: A Qualitative Study
}

\author{
Eyüp Y1lmaz ${ }^{1}$ \\ Adnan Menderes \\ University
}

\author{
Selma Yel \\ Gazi University
}

\author{
Mark D. Griffiths ${ }^{3}$ \\ Nottingham Trent \\ University
}

\begin{abstract}
Video gaming has now become very popular among children and adolescents. Because of the increasing use of videogames, the debate concerning the effects of video games has been ongoing, particularly in terms of gamers' social lives. This study explores the impact of heavy gaming students on their peers and teachers in the school environment. For this purpose, focus-group and face-to-face interviews have been carried out using semi-structured interview forms developed by the research team. The data have been collected from 21 participants comprised of three heavy gaming students, 16 peers, and two teachers. The findings indicate heavy gamers to display problematic behaviors including communication and behavioral problems within the school environment. Results also show heavy gaming students to prefer staying at home and playing videogames rather than attending school activities. Heavy gamers mostly prefer spending time with other heavy gamers or with male peers because they have mutual topics they can talk about (video games, their game talents, soccer, outdoor games etc.), which they are unable to with girls. According to the teachers, heavy gamers have low-school performance. However, the English teacher emphasized the positive effects of video gaming on students' English vocabulary.
\end{abstract}

Keywords

Videogames • Problematic gaming • Heavy videogame playing • Excessive videogame playing • Gaming perceptions $\bullet$ School environment $\bullet$ Children

\footnotetext{
1 Correspondence to: Eyüp Yılmaz, Division of Primary School Education, Adnan Menderes University, Aydın Turkey. Email: eyup.yilmaz@adu.edu.tr

2 Division of Primary School Education, Gazi University, Ankara Turkey. Email: selmayel@gazi.edu.tr

3 International Gaming Research Unit, Psychology Department, Nottingham Trent University, Nottingham UK. Email:mark.griffiths@ntu.ac.uk

To cite this article: Yılmaz, E., Yel, S., \& Griffiths, M. D. (2018). The impact of heavy (excessive) video gaming students on peers and teachers in the school environment: A qualitative study. Addicta: The Turkish Journal on Addiction, 5, 147-161. http://dx.doi.org/10.15805/addicta.2018.5.2.0035
} 
Through technological development and the Internet's widespread accessibility, gaming within the digital environment has become very popular all over the world for children and adolescents (Y1lmaz, Griffiths, \& Kan, 2017). In today's society, children can now easily access technological devices from an early age, and those who play them view them as entertaining and exciting (Griffiths, 2003; Wan \& Chiou, 2006). Many factors, including increasingly sophisticated systems, communicational characteristics, and photo-realistic graphics, explain the popularity of videogames (Braun et al., 2016). Such features increase the amount of time children spend playing the new generation of video games.

In recent years, videogame play has rapidly become many individuals' favorite pastime and the global gaming industry has grown at a quick pace. While worldwide software game sales were $\$ 70$ billion in 2012, this amount reached over $\$ 100$ billion in 2017 and is expected to reach $\$ 115$ billion in 2018 (Global Games Market Report, 2017). Research shows approximately one-third of gamers' $(29 \%)$ to be under 18 years old, which therefore comprises a significant minority of children and adolescents (Entertainment Software Association, 2017).

The amount of time children and adolescents spend on videogames has increased steadily (Yilmaz et al., 2017). Educators and parents have noticed this increasing popularity of videogame play among youths (Gentile, 2009), especially in terms of its potential psychosocial impact on players. Although many positive benefits exist for playing videogames, its potentially damaging effects among a minority of individuals has been noted by numerous scholars. These concerns have included unfavorable content such as sex and violence (Benrazavi, Teimouri, \& Griffiths, 2015); videogame addiction among some excessive gamers (Griffiths \& Meredith, 2009; Kuss \& Griffiths, 2012a, 2012b); and increased aggression, anxiety, and medical consequences (Anderson \& Murphy, 2003; Charlton, 2002; Chumbley \& Griffiths, 2006; Wallenius et al., 2007). Furthermore, Jansz and Martens (2005) indicated the ubiquity of violence in videogames and risk of social isolation as a result of video gaming issues to dominate these debates.

Studies have shown one of educators and parents' main concerns regarding videogame play to be the potential for low scholastic performance and social competence (Brunborg et al., 2013; Gentile, 2009; Y1lmaz, 2018). In addition, Griffiths (2010) reported that high frequency videogame play may compromise the ability to gain social skills and that oft-playing gamers exhibit more social anxiety than lowplaying gamers. However, a number of studies have shown that online gaming can have a positive socializing experience where players develop meaningful friendships (Cole \& Griffiths, 2007; Yee, 2006); this can improve their relationships with others in both the virtual and real world. Research has shown the social connections formed 
in online games to be able to lead to meeting face-to-face (Cole \& Griffiths, 2007). A number of reasons why online friendships form while playing online games exists. Furthermore, advanced gaming skills allow players to earn respect and reputations among fellow players (Huanhuan \& Su, 2013). Consequently, players (including children) often prefer to share their game experiences with peers, rather than with parents or teachers (Bourgonjon et al., 2011).

Understanding children's social relationships more holistically through their videogame play will likely provide important contributions to the existing literature. We believe that the school environment to be an appropriate place for carrying out qualitative research for two reasons. First, some excessive gamers are quite likely to have virtual friendships with their schoolmates, and excessive gaming provides opportunities for them to display their gaming skills and earn respect and reputations among other players. Second, examining children's relationships in a school environment is imperative for gathering in-depth information, as it is a key environment for systematically collecting rich data concerning social relationships among children.

Much of the current research has focused on the psychosocial impact of gaming. For instance, research has demonstrated that increased time spent on video gaming may lead to loss of control over use and strong urges to play when unable to (Bargeron \& Hormes, 2017; Carras et al., 2017; Gentile et al., 2011; Mentzoni et al., 2011). At this point, heavy, or excessive, gaming should be distinguished from problematic gaming. Gamers can play excessively without experiencing problems (Griffiths, 2010). Problematic gaming has been conceptualized as a loss of control over use (Van Rooij, 2010). Desai et al. (2010) considered problematic gaming as a non-substance-related addiction, or an impulse-control disorder. As with taking drugs, video gaming can lead to hedonic sensations that modify an individual's mood state. However, distinguishing which behaviors may result in problematic use is not always easy, even when taken to excess (Kuss, Griffiths, Karila, \& Billeux, 2013). Heavy gaming's effects might differ based upon gamers' psychological profiles and lifestyles (Rooij et al., 2010). This study does not formally assess gaming addiction, and therefore heavy gamers may or may not have problems associated with excessive gaming. The heavy gamers in the study simply imply those who play four or more hours each day.

\section{Method}

\section{Design}

The present study utilizes a focus-group case-study design. Merriam (2009) defined a case study as the in-depth examination and description of a limited system. In such studies, researchers attempt to explain a program, event, activity, process, or one or more personal events in depth (Creswell, 2009). One of the main benefits 
of the focus-group interview is that it can encourage people who are reluctant to be interviewed on their own or feel they have nothing to say to participate (Kitzinger, 1995); this provides rich data to the investigators.

\section{Participants}

The participants are comprised of 20 people, 18 fourth-grade students $(M=$ 9.4 years old) and their two teachers (classroom teacher and English teacher). A multistage sampling method was used to recruit the study group. In the first stage, convenience sampling was used for practical reasons in order to save time (Yildırım $\&$ Şimşek, 2011) selecting a public school in the second stage, criterion sampling was utilized and three participants who met the criterion of spending four or more hours playing videogames a day comprised the heavy gamer group. The logic of criterion sampling is to study cases that meet some predetermined criterion of importance (Patton, 1990). The three heavy gamers are all male. The remaining 15 classmates are comprised of eight girls and seven boys. One female student was unable to attend the study due to a physical disability. The classroom teacher is male with 10 years of experience. He has been teaching these students for four years (from first to fourth grade). The English teacher is female and also a parent of one of the heavy gaming students. She has 18 years of professional experience and has been working at the same school since 2002. Consequently, both teachers have enough experience with the study group to provide in-depth data.

\section{Instruments}

Two different interview forms, the Peer Association Form and the Teacher-Student Association Form, were developed by the authors for data collection purposes. The relevant literature was reviewed (i.e., Bargeron \& Hormes, 2017; Birch \& Ladd, 1997; Carras et al., 2017; Dopp \& Cain, 2012; Griffiths, 2003, 2008, 2010; Grüsser, Thalemann, \& Griffiths, 2007; Jansz \& Martens, 2005; Klein \& Kuiper, 2006; Van Rooij, 2010) in order to determine the sub-components of peer and student-teacher associations and provide insight into the investigated topics. Once the draft interview forms were created, they were sent to four field experts (a linguist, a measurement and assessment researcher, a qualitative researcher, and a researcher specializing in videogames) to provide the face validity as well as ensure language fluency and clarity. The draft interview forms were then revised based on the experts' feedback. Furthermore, two different classroom teachers examined the final version of the interview forms to ensure that fourth-grade students can understand them. Both interview forms resemble each other in style and structure. Only the demographic variables and way questions are asked differ from each other. For instance, the Teacher-Student Association Form contains extra demographic questions about 
teachers' professional experience and amount of time spent with their students. In addition, the interview questions have been adapted based on the respondent. For instance, teachers had the interview question, "What can you tell us about the heavy gamer students in your class?" whereas the focus groups had the question, "What can you say about your classmates who are heavy gamers?"

\section{Procedure and Data Collection Process}

Before starting the implementation process, necessary permissions were sought by applying to the provincial directorate of national education and contacting school management. Additionally, the classroom teacher helped to send the parents a consent form for obtaining parental permission. A brief pre-interview was performed with the fourth-grade classroom teachers to decide which classroom to work with after having received the necessary approvals. Following this, fourth-grade students were interviewed individually using a basic structured interview form on video gaming developed by the investigators. Interviews were carried out in an appropriate room the school management provided. Next, the boys meeting the heavy gaming criterion were identified. Following this, the rest of the students were grouped in fives, and focus-group interviews were held to determine the associations with heavy gaming students through another basic researcher-developed interview form. The same focus-group interview was performed with the three males in the heavy gamer group.

The Student-Teacher Association Form has been used to explore the heavily gaming students' scholastic performance and relationships with teachers. Individual face-to-face interviews were held with the class teacher and English teacher. Each focus-group interview took an average of 30-35 minutes, while individual interviews lasted approximately 15-20 minutes each. All interviews have been audio-recorded with participants' permission so that an accurate record of the data collected can exist. The interviews with the different stakeholders were carried out by making appointments; all were completed within 15 days. Heavy gamers' parents were also interviewed to corroborate the accuracy of their data.

\section{Data Analysis}

Data extracted from the in-depth interviews have been translated verbatim from the recordings. Afterward, coders with experience in qualitative analysis methods encoded the interview texts separately using content analysis technique. Weber (1990) indicated that content analysis goes beyond merely counting words for intensely examining language in order to classify large amounts of text into an efficient number of categories that represent similar meanings. After the two coders encoded all data, an inter-rater reliability index was calculated (Miles \& Huberman, 1994). The reliability index was found to be $87 \%$ (higher than the recommended $70 \%$ ). The 
categories (themes) and sub-categories have been acquired based on these codes. The NVIVO 12 computer software package was utilized during the analytical process.

\section{Results}

The following section provides each participant with coded pseudonyms to facilitate anonymity. The two teachers are tagged as CT (classroom teacher), and ET (English teacher). The heavy gamers' classmates are noted as S1, S2, S3, and so on, while the heavy gamers are noted as HG1, HG2, and HG3. Details on HG1, HG2 and HG3 are described briefly in more detail below:

HG1. This participant has a personal computer and tablet for videogame playing. He said he plays video games an average of three hours per day during the week and more than five hours per day on weekends. However, his mother said he plays videogames for an average of 5 hours a day during the week, which could be much more on weekends. He reported that he likes playing videogames very much because he finds them entertaining and exciting. He also said he prefers playing videogames instead of playing with his friends. He has no close friendships in his neighborhood. His favorite games are Clash of Clans, Pro-Evolution Soccer 2013, and Wolf Team. He admitted that he sometimes pretends to be his videogame characters, trying to act like them, and that this could cause problems between himself and his family members.

HG2. This participant has a personal tablet and laptop computer shared with his older sister. He said he prefers playing video games on his tablet on Sundays, but plays on the laptop the rest of the week. He mostly plays Grand Theft Auto 5; however, he sometimes prefers playing Minecraft. He claimed to play videogames around three hours a day during the week and four hours a day during the weekend. However, his parents reported that he plays videogames much longer than he claims. He said he wants to play videogames all the time, he likes it that much. He can be aggressive towards family members when prevented from playing videogames and argues with his older sister about who has the right to use the laptop to play videogames. He does not believe video gaming to negatively affect his scholastic performance, even though he has had some problems doing homework. He reported the videogame characters he plays to sometimes haunt his dreams.

HG3. This participant has a personal computer and tablet shared with a brother and sister. He claims to play videogames 4-5 hours a day during the week, going up to more than 7 hours a day on weekends which is confirmed by his parents. He prefers playing Grand Theft Auto 5, Clash of Clans, Pro-Evolution Soccer 2013, and sometimes Minecraft. He always has disagreements with family members, and these sometimes turn into physical fights. He reported that he can become very aggressive and irritated if he is prevented from playing videogames. He does not think videogame 
playing is related to his low-school performance. He reported sometimes imagining the classroom as a videogame environment, trying to act as the game characters he plays against classmates, and maybe arguing with them because of this.

\section{Heavy Gamers' Impact on Their Peers and Teachers}

The focus-group interviews with the students and face-to-face interviews with the teachers were analyzed using content analysis, and codes have been grouped into four categories (scholastic performance, communication, problems, and social relationships) with 13 sub-categories (peer support, low school performance, and foreign language development; poor communication and game-connected communication; behavioral problems, verbal problems, affective problems, and selfcontrol problems; and exclusion, desire for social isolation, connections through common-interest, and personal character).

\section{Scholastic Performance}

The category of Scholastic Performance comprises three sub-categories: lowscholastic performance, peer support, and foreign language development. During the focus group interviews, the students indicated heavy gamers to generally demonstrate low scholastic performance. Although various reasons exist for this that can be cited as reasons, like hyperactivity, lack of motivation, and not listening to the teacher, students cited playing video games too much as the main reason for heavy gamers' low-scholastic performance. For instance, S3 reported, "I know, his (HG2's) mother does his homework while he plays video games. My mother heard his mother say this at the parent-teacher meeting. That is how I know."

Furthermore, some students stated trying to help heavy gamers do their homework and worksheets. S11 indicated, "I think students who play videogames all the time have low scholastic performance as they feel they are in the game world during school because they hang out for a very long time in the game world."

This assertion was affirmed by HG1, who said:

I know I play video games a lot, and this causes low scholastic performance. At some point, I feel hopeless because game characters are always on my mind even during exams. I find myself dreaming about the game characters and scenes, and when the exam is over, I return to the real world.

This was also confirmed by the $\mathrm{CT}$, who stated heavy gamers to not pay attention to his teaching, to be unaware of their learning responsibilities, and to make no effort to realize their educational potential. CT emphasized parental conflicts and indifference toward their children to be the main reasons for this situation: 
I know these three students share a mutual misfortune and all of them have problematic experiences with their parents. Their mothers and fathers have no interest in them, which strikes me as why these children prefer playing video games, to avoid their parental problems.

On the other hand, the ET mentioned the benefits of playing video games, especially in terms of learning English as a foreign language. She reported video games to mostly involve English vocabulary, and heavy gamers learn/become acquainted with these words while playing videogames. This helps her teach them English. In addition, being familiar with English words helps them be highly motivated pupils when learning English.

\section{Communication}

The category of communication is comprised of two sub-categories: poor communication and game-connected communication. The heavy gamers reported they like to talk about the games, game characters, their game levels, and game challenges among themselves more than talking to others. Similarly, girls in the focus group interviews particularly mentioned not being able to or having difficulty communicating with the heavy gamers. S7 reported:

When I try communicating with them (HGs), the conversation is always somehow connected to video games, and this is boring to me. I don't want to talk with them about games. I don't wonder what they are doing in the games or how they are overcoming obstacles. I just want to talk about our daily life, school performance, or anything else besides video games.

The situation was a bit more positive for male students, as they have mutual subjects to talk about such as soccer, outdoor games, or video games (because they also play video games, just not as much as the heavy gamers). Communication between heavy gamers and teachers is relatively poor. The teachers indicated not having strong enough communication with them and the students' personality to also be determining factors in relation to this. For instance, HG3 is more sociable and extroverted compared to HG1 and HG2. HG3 always attempts to prove himself, and hence has slightly better communication skills than the other two heavy gamers.

\section{Problems}

The heavy gamers' peers and teachers referred to certain problems in their relationships during the interviews: affective problems, verbal problems, selfcontrol problems, and behavioral problems. Focus group interviews indicate peers to suffer from heavy gamers' bullying and physical assaults, claiming they do not obey classroom rules and neglect their educational and social responsibilities. Verbal problems include acts such as teasing and making fun of other individuals, using nicknames, and swearing. As S15 noted, "(HG1) broke my glasses while playing soccer. I was exposed to a harsh foul from him. I fell down and my glasses broke." 
S7 indicated, "The (HG group) are nearly at pro-gamer status, and this is a kind of superiority indicator among them. They praise themselves by talking about their game talents or levels. They also may make fun of low-level gamers."

The heavy gamers' teachers dwelled on affective and self-control problems. CT reported, "We have some temper problems with these boys. They can be aggressive or irritable much quicker than you would expect them to be, and this makes things difficult for me, especially in terms of classroom management."

In addition, he mentioned getting them to pay attention to what is being taught to be difficult because they have problems focusing due to constantly thinking about videogames or characters. Furthermore, the ET drew attention to heavy gamers' affective problems, such as tendencies toward violence and struggling for superiority among classmates, especially in terms of game talents.

\section{Social Relationships}

Some students, particularly girls, indicated having begun to develop adverse reactions to the heavy gamers due to the aggressive and irresponsible behaviors they show; these students do not want to deal with them if they don't have to. Some of them stated HG1 and HG2 to not pay attention to hygienic care sometimes, resulting in their being excluded from the classroom. During the interviews with heavy gamers, their desire for isolation from their classmates was found to have an important place in how they select social relationships. The heavy gamers stated preferring to spend time with each other or their male peers talking about video games or playing ball games instead of being part of social activities or spending time with others. Both teachers stated the heavy gamers' personalities to often dictate their relationships. The ET reported HG1 and HG2 to be relatively withdrawn and to prefer being alone compared to HG3. HG3 was described as being more enterprising, sociable, and self-confident and having a healthy relationship with the ET, who said, "(HG3) is so willing to do things. For instance, if the projector or computer needs to be set up, he immediately raises his hand and asks me if he can help."

The CT emphasized that constantly engaging with videogames has created a tendency toward loneliness; they prefer staying at home instead of participating in out-of-school activities. CT noted:

I can say they communicate with each other, but they are usually alone. They sometimes play soccer with their male peers during break time, but they have no common activity with others apart from that. I think they have a tendency toward loneliness. 


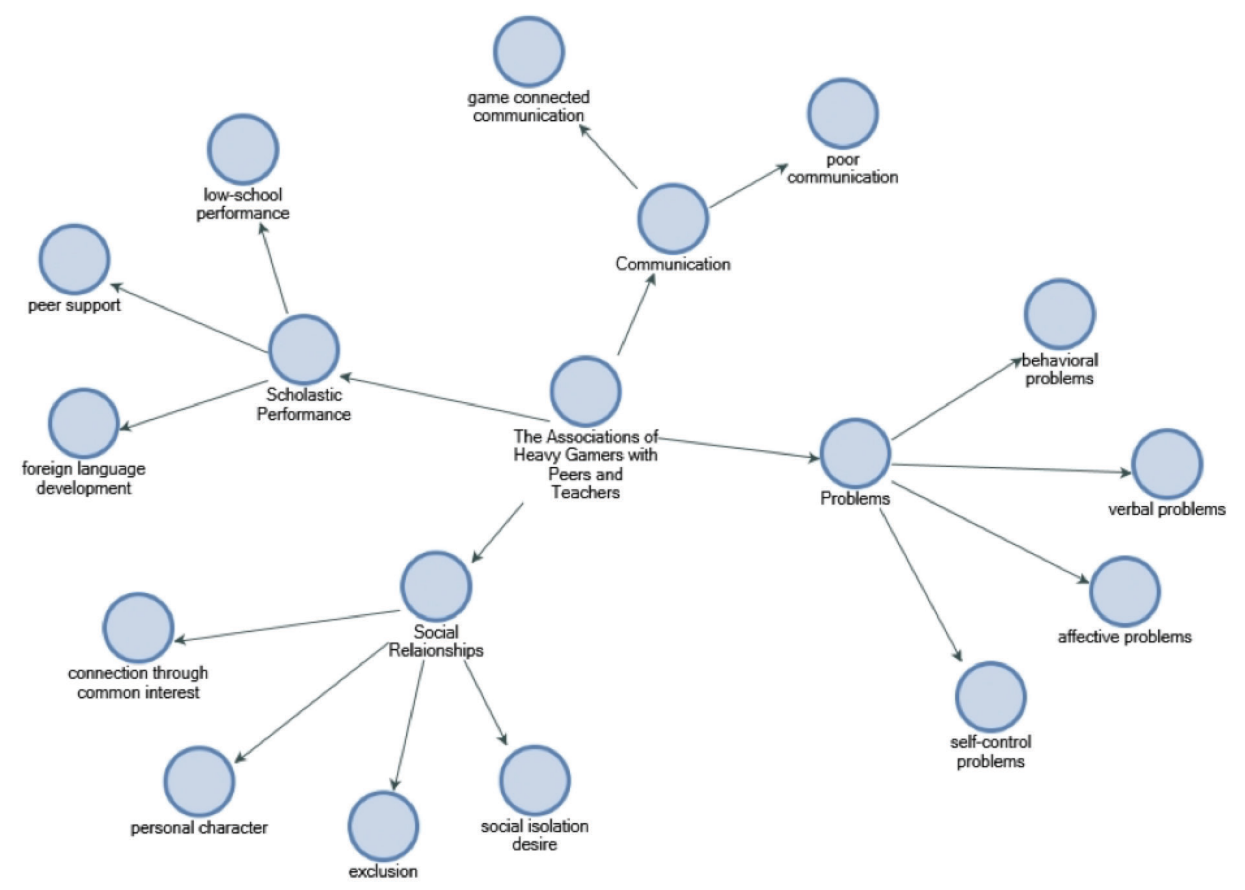

Figure 1. Model displaying the impact heavy gamers have on peers and teachers.

\section{Discussion}

The effects of playing video games among children and adolescents appears to be one of the most discussed topics by current educators and parents in relation to its impact on scholastic activity (Griffiths, 2014). Moderate videogame playing appears to have little or no negative psychosocial impact on those who engage in it, and research indicates individuals who have problems to be in the minority and only to arise from heavy and excessive play (Kuss \& Griffiths, 2012b). The present study is novel in that it looks at the impact of heavy gaming by a few students in one class from the perspective of teachers and pupils.

The findings of this qualitative study on heavy gamers' impact on their peers and teachers based on interviews and focus groups have produced four main themes: low scholastic performance, communication issues, problems in the classroom, and selective social relationships. The findings according to their peers and teachers indicate heavy gamers have low-scholastic performance. Some students have tried helping the heavy gamers increase their academic achievement. These findings confirm those of previous survey research on the negative relationship between problematic gaming and school performance (Hastings et al., 2009; Skoric, Ching Teo, \& Neo, 2009). Other related research has demonstrated problematic gaming to 
result in lower school success and school truancy (Rehbein, Kleimann, \& Mossle, 2010). In this study, the classroom teacher could not get heavy gamers to concentrate on the material during lessons. However, there were some positives. The English teacher noted that playing video games appears to help students learn English words, and this contributes positively to their foreign language learning by increasing their motivation toward the English course. Griffiths (2008) also pointed out the educational importance of videogames, reporting them to be able to be beneficial for teaching issues as long as the teachers evaluate the specific benefits games might have when allowing students to play them in an educational context. Furthermore, educational videogames have been found to enhance students' motivation toward the subjects being taught, although these studies examined moderate videogame playing (Anyaegbu, Tin, \& Li, 2012) rather than excessive gaming.

The communication among heavy gamers is somewhat predictably related to videogame playing. The heavy gamers generally prefer communicating amongst themselves; if they do talk to others it was usually other males on the topic of videogame playing or sports (particularly soccer). The girls indicated having poor communication with the heavy gamers and preferring to not connect socially with them because the conversation content bores them. According to the teachers, the students' personal characteristics (personality) are what have the greatest effect on the quality of social communication, but videogame playing can contribute to their personality characteristics and vice-versa. Lachlan and Maloney (2008) found players with higher extroversion to engage in more violent interactions in their videogames. HG3 is more extroverted compared to HG1 and HG2, and the games he plays (Grand Theft Auto 5, Clash of Clans) contain the most violent interactions. However other studies have found no association between extroversion and frequency of playing violent videogames (Anderson et al., 2004; Bartholow et al., 2005).

Both male and female students mentioned their heavy gaming peers to engage in behavioral (e.g., bullying, physical assaults) and verbal problems (e.g., teasing, swearing), and how much they have negatively suffered from these actions. Some studies examining the violent content in videogames have reported neurotic individuals to prefer playing more violent video games (Chory \& Goodboy, 2011). Other studies have reported playing violent videogames to increase aggression, even when arousal and affect are controlled (Anderson et al., 2004). In the present study, both teachers emphasized the affective and self-control problems among heavy gamers.

Poor social communication between the girls and heavy gamers led the girls to develop adverse reactions. The personal hygiene problems of heavy gamers also led them to be excluded from their peer groups, particularly the girls. Predictably, the heavy gamers' social relationships appear strongest with other heavy gamers. Cole and Griffiths (2007) reported massively multiplayer online role-playing 
games (MMORPGs) to often provide the opportunity to gamers to develop lifelong friendships and partnerships. Wright et al. (2002) indicated the online videogame world to bring together like-minded individuals and such individuals to be able to create innovations by developing game-specific speech or non-verbal (logo design) actions. Furthermore, they reported heavy gamers' connection with male peers to be much better than with females. In the present study, the ET emphasized the effect of heavy gamers' personal characteristics on their relationships while the CT focused on their tendency toward loneliness.

The present study is not without limitations. Participant's responses toward the interview questions have been presumed sincere and candid, but self-report is open to many well-known biases, such as social desirability and memory recall biases, that may impact the veracity of the findings. Only two teachers participated because some of the heavy gamers' teachers said they did not know enough about the students (e.g., the Religious Culture teacher and the Ethics teacher). Being a qualitative study comprising a small number of Turkish participants, the generalizability to other classes and cultures is arguably weak, although the in-depth nature of the data provides far more detail than survey approaches.

The present study is limited by the fact that only three of the participants are heavy gamers, yet even though small in number, their effect on the in-class social relationships and perceptions is arguably sizeable. Future studies will need to replicate and extend the findings presented here using bigger samples from schools in other countries and jurisdictions. In addition, the findings of this study are cross-sectional and could be improved by incorporating longitudinal designs.

Previous research indicates a lack of qualitative studies to have existed that examine the impact of heavy gamers on their peers and teachers within the school environment. This makes the present study novel. Also, the corroborating evidence from parents about the heavy gamers is also a novel aspect and strengthens the validity of the findings, knowing that the heavy gamers have also been perceived the same by their parents. The study demonstrates that gaming can be an excessive activity even for those who have yet to reach puberty. The present study shows videogames to be able to influence the behaviors of children 10 years and younger, and that their behavior can have negative effects on those around them.

\section{References}

Anderson, C. A., Carnagey, N. L., Flanagan, M., Benjamin, A. J., Eubanks, J., \& Valentine, J. C. (2004). Violent video games: Specific effects of violent content on aggressive thoughts and behavior. Advances in Experimental Social Psychology, 36, 199-249.

Anderson, C. A., \& Murphy, C. R. (2003). Violent video games and aggressive behavior. Aggressive Behavior, 29, 423-429. 
Anyaegbu, R., Ting-JESSY, W., \& Li, Y. (2012). Serious game motivation in an EFL classroom in Chinese primary school. TOJET: The Turkish Online Journal of Educational Technology, 11(1), 154-165.

Bargeron, A. H., \& Hormes, J. M. (2017). Psychosocial correlates of internet gaming disorder: Psychopathology, life satisfaction, and impulsivity. Computers in Human Behavior, 68, 388-394.

Bartholow, B. D., Sestir, M. A., \& Davis, E. B. (2005). Correlates and consequences of exposure to video game violence: Hostile personality, empathy, and aggressive behavior. Personality \& Social Psychology Bulletin, 31(11), 1573-1586.

Benrazavi, R., Teimouri, M., \& Griffiths, M. D. (2015). Utility of parental mediation model on youth's problematic online gaming. International Journal of Mental Health and Addiction, 13, 712-727.

Birch, S. H., \& Ladd, G. W. (1997). The teacher-child relationship and children's early school adjustment. Journal of School Psychology, 35(1), 61-79.

Braun, B., Stopfer, J. M., Müller, K. W., Beutel, M. E., \& Egloff, B. (2016). Personality and video gaming: Comparing regular gamers, non-gamers, and gaming addicts and differentiating between game genres. Computers in Human Behavior, 55, 406-412.

Brunborg, G. S., Mentzoni, R. A., Melkevik, O. R., Torsheim, T., Samdal, O., Hetland, J. ... Pallesen, S. (2013). Gaming addiction, gaming engagement, and psychological health complaints among Norwegian adolescents. Media Psychology, 16(1), 115-128.

Bourgonjon, J., Valcke, M. Soetaert, R., de- Wawer, B., \& Schellens, T. (2011). Parental acceptance of digital game-based learning. Computers \& Education, 57, 1434-1444.

Carras, M. C., Rooij, A. J. V, Van de Mheen, D., Musci, R., Xue, Q. L., \& Mendelson, T. (2017). Video gaming in a hyperconnected world: A cross-sectional study of heavy gaming, problematic gaming symptoms, and online socializing in adolescents. Computers in Human Behavior, 68, 472-479.

Charlton, J. P. (2002). A factor analytic investigation of computer 'addiction' and engagement. British Journal of Psychology, 93(3), 329-344.

Chory, R. M., \& Goodboy, A. K. (2011). Is basic personality related to violent and non-violent video game play and preferences? Cyberpsychology, Behavior, and Social Networking, 14(4), 191-198.

Chumbley, J., \& Griffiths, M. D. (2006). Affect and the computer game player: the effect of gender, personality, and game reinforcement structure on affective responses to computer gameplay. CyberPsychology \& Behavior, 9(3), 308-316.

Cole, H. \& Griffiths, M. D. (2007). Social interactions in Massively Multiplayer Online RolePlaying gamers. CyberPsychology \& Behavior, 10, 575-583.

Creswell, J. W. (2009). Research design: Qualitative, quantitative, and mixed methods approaches (3rd ed.). Los Angeles, CA: Sage.

Desai, R. A., Krishnan-Sarin, S., Cavallo, D., \& Potenza, M. N. (2010). Video-gaming among high school students: Health correlates, gender differences, and problematic gaming. Pediatrics, 126(6), e1414-e1424.

Dopp, A. R., \& Cain, A. C. (2012). The role of peer relationships in parental bereavement during childhood and adolescence. Death Studies, 36(1), 41-60.

Entertainment Software Association. (2017). Essential facts about the computer and video game industry full report (2017). Retrieved from http://www.theesa.com/wp-content/uploads/2017/04/ EF2017_FinalDigital.pdf

Gentile, D. (2009). Pathological video-game use among youth ages 8 to 18: A national study. Psychological Science, 20(5), 594-602. 
Gentile, D. A., Choo, H., Liau, A., Sim, T., Li, D., Fung, D., \& Khoo, A. (2011). Pathological video game use among youths: A two-year longitudinal study. Pediatrics, 127(2), 319-331.

Global Games Market Report (2017). 2017 Global games market report: Trends, insights, and projections towards 2020. Retrieved from http://progamedev.net/wp content/uploads/2017/06/ Newzoo_Global_Games_Market_Report_2017_Light.pdf

Griffiths, M. D. (2003). The therapeutic use of videogames in childhood and adolescence. Clinical Child Psychology and Psychiatry, 8(4), 547-554.

Griffiths, M. D. (2008). Adolescent video game playing: Issues for the classroom. Education Today, $60(4), 32-34$.

Griffiths, M. D. (2010). Computer game playing and social skills: a pilot study. Aloma: Revista de Psicologia, Ciències de l'Educació i de l'Esport, 27, 301-310.

Griffiths, M. D. (2010). The role of context in online gaming excess and addiction: Some case study evidence. International Journal of Mental Health and Addiction, 8, 119-125.

Griffiths, M. D. (2014). Gaming addiction in adolescence (revisited). Education and Health, 32, 125-129.

Griffiths, M. D., \& Meredith, A. (2009). Videogame addiction and treatment. Journal of Contemporary Psychotherapy, 39(4), 47-53.

Grüsser, S. M., Thalemann, R., \& Griffiths, M. D. (2006). Excessive computer game playing: Evidence for addiction and aggression? CyberPsychology \& Behavior, 10(2), 290-292.

Hasting, E. C., Karas, T. L., Winsler, A., Way, E., Madigan, A., \& Tyler, S. (2009). Young children's video/computer game use: Relations with school performance and behavior. Issues in Mental Health Nursing, 30(10), 638-649.

Huanhuan, L., \& Su, W. (2013). The role of cognitive distortion in online game addiction among Chinese adolescents. Children and Youth Services Review, 35, 1468-1475.

Jansz, J., \& Martens, L. (2005). Gaming at a LAN event: the social context of playing video games. New Media \& Society, 7(3), 333-335.

Kitzinger, J. (1995). Qualitative research: Introducing focus groups. British Medical Journal, 311, 299-302.

Klein, D. N., \& Kuiper, N. A. (2006). Humor styles, peer relationships, and bullying in the middle childhood. Humor - International Journal of Humor Research, 19(4), 383-404.

Kuss, D., \& Griffiths, M. D. (2012). Adolescent online gaming addiction. Education and Health, 30(1), 15-17.

Kuss, D. J. \& Griffiths, M. D. (2012). Online gaming addiction in adolescence: A literature review of empirical research. Journal of Behavioral Addictions, 1, 3-22.

Kuss, D., Griffiths, M. D., Karila, L., \& Billieux, J. (2013). Internet addiction: A systematic review of epidemiological research for the last decade. Current Pharmaceuntical Design, 20(25), 4026-4052.

Lachlan, K. A., \& Maloney, E. K. (2008). Game player characteristics and interactive content: Exploring the role of personality and telepresence in video game violence. Communication Quarterly, 56(3), 284-302.

Mentzoni, R. A., Brunborg, G. S., Molde, H., Myrseth, H., Skouyeroe, K. J. M., Hetland, J., \& Pallesen, S. (2011). Problematic video game use: Estimated prevalence and associations with mental and physical health. Cyberpsychology, Behavior, and Social Networking, 14(10), 591-596.

Merriam, S. B. (2009). Qualitative research: A guide to design and implementation (3rd ed.). San Francisco, CA: Jossey-Basse 
Miles, M. B., \& Huberman, A. M. (1994). Qualitative data analysis: An expanded sourcebook. London, UK: Sage.

Patton, M. (1990). Qualitative evaluation and research methods. Beverly Hills, CA: Sage.

Rehbein, F., Kleimann, M., \& Mossle, T. (2010). Prevalence and risk factors of video game dependency in adolescence: Results of a German nationwide survey. CyberPsycology \& Behavior and Social Networking, 13(3), 269-277.

Skoric, M. M., Ching Teo, L. L., \& Neo, R. L. (2009). Children and video games: Addiction, engagement and scholastic achievement. CyberPsycology \& Behavior, 12(5), 565-572.

Van Rooij, A. J., Schoenmakers, T. M., Vermulst, A., van den Eijnden, R. J. J. M., \& van de Mheen, D. (2011). Online video game addiction: Identification of addicted adolescent gamers. Addiction, 106, 205-212.

Wallenius, M., Punamäki, R. L., \& Rimpelä, A. (2007). Digital game playing and direct and indirect aggression in early adolescence: The roles of age, social intelligence, and parent-child communication. Journal of Youth and Adolescence, 36(3), 325-336.

Wan, C. S., \& Chiou, W. B. (2006). Why are adolescents addicted to online gaming? An interview study in Taiwan. CyberPsychology \& Behaviour, 9(6), 762-766.

Weber, R. P. (1990). Basic content analysis. Beverly Hills, CA: Sage.

Wright, T., Boria, E., \& Breidenbach, P. (2002). Creative player actions in FPS online video games. Playing Counter-Strike. Game Studies, 2(2), 103-123.

Yee, N. (2006). Motivations of play in online games. CyberPsychology \& Behavior, 9, 772-775.

Yıldırım, A., \& Şimşek, H. (2011). Sosyal bilimlerde nitel araştırma yöntemleri [Qualitative research methods in the social sciences] (8th ed.). Ankara, Turkey: Seçkin.

Y1lmaz, E. (2018). Teaching with educational computer games according to classroom teachers and candidate teachers' opinion. Gazi University Journal of Gazi Education Faculty, 38(1), 263-298.

Yılmaz, E., Griffiths, M. D., \& Kan, A. (2017). Development and validation of Video Game Addiction Scale for Children (VASC). International Journal of Mental Health and Addiction, 15(4), 869-882. 